\title{
Statistical Analysis of Isothermal Cold Starts of PEFCs: Impact of Gas Diffusion Layer Properties
}

\author{
Johannes Biesdorf, a A. Forner-Cuenca, ${ }^{\text {a,* }}$ M. Siegwart, ${ }^{\text {a T. J. Schmidt, }},{ }^{\text {a,b,*** }}$ \\ and Pierre Boillat ${ }^{\mathrm{a}, \mathrm{c}, * *, \mathrm{z}}$ \\ ${ }^{a}$ Laboratory of Electrochemistry (LEC), Paul Scherrer Institute (PSI), 5232 Villigen PSI, Switzerland \\ ${ }^{b}$ Laboratory of Physical Chemistry, ETH Zürich, 8093 Zürich, Switzerland \\ ${ }^{c}$ Neutron Imaging and Activation Group (NIAG), Paul Scherrer Institute (PSI), 5232 Villigen PSI, Switzerland
}

\begin{abstract}
In this paper, we present experimental results about the influence of a hydrophobic coating of gas diffusion layers (GDL) and the existence of a micro porous layer (MPL) on the cold start capability of Polymer Electrolyte Fuel Cells (PEFC). The experiments were performed on five different cell configurations with an active area of $1 \mathrm{~cm}^{2}$ including GDLs of $0,5,20 \mathrm{wt} \%$ PTFE with and without MPL. Two different experiments were realized: First, a statistical analysis of more than 700 isothermal cold starts was performed to analyze the stochastic freezing behavior of supercooled water inside the fuel cells. Second, a certain number of cold starts were investigated with high-resolution neutron radiography in order to understand the implications of the water distribution on the freezing mechanism. Especially at low coating loads, it was found that cell-to-cell variations are more dominant than variations of the materials. In contrast, a significantly reduced variability between the individual cells as well as a general reduction of the probability of cell failure was observed at high coating loads. The observed effects can be mainly explained by changed morphology of the investigated materials. Regarding the existence of an MPL, only minor effects were observed which could be assigned to a different local distribution of water in the porous layers.

(C) The Author(s) 2016. Published by ECS. This is an open access article distributed under the terms of the Creative Commons Attribution 4.0 License (CC BY, http://creativecommons.org/licenses/by/4.0/), which permits unrestricted reuse of the work in any medium, provided the original work is properly cited. [DOI: 10.1149/2.1071610jes] All rights reserved.
\end{abstract}

Manuscript submitted May 16, 2016; revised manuscript received August 3, 2016. Published September 2, 2016.

In the last years, the first generation of automotive Polymer Electrolyte Fuel Cells (PEFC) has been commercialized. ${ }^{1,2}$ However, several improvements regarding degradation, performance, and cold start capability have to be achieved to ensure a reliable and durable operation even under extreme ambient operating conditions. ${ }^{3}$ The cold start capability of fuel cells has been widely studied on lab-scale $e^{4-7}$ as well as on technical fuel cells. ${ }^{8,9}$ It has been reported that water does not deposit as ice inside fuel cells; it is produced in its supercooled aggregate state $e^{4,5,7,10}$ and the phase transition to ice occurs randomly. This has been proven indirectly based on the location of water accumulation (see Ref. $5,7,10$ ) but also directly by energy selective neutron radiography. ${ }^{4}$

In a theoretical study, Ishikawa et al. ${ }^{11}$ pointed out that the transition from supercooled to frozen water is dependent on several parameters like e.g. the water cluster volume, the hydrophobicity of the substrate as well as its microstructure. This theoretical study is in good agreement with recent experiments ${ }^{12}$ of our group, where local variations of the material itself led to significant variations of the cold start capability. If these features that promote the freezing can be identified and removed, the cold start capability can be significantly improved for lab-scale as well as for technical fuel cells. In order to identify factors improving the cold start capability of fuel cells, two parameters of gas diffusion layers (GDL) are studied in this paper: (1) the influence of a hydrophobic coating and (2) the presence of a micro porous layer (MPL).

Although various researchers investigated the cold start capability, the influence of material properties is rarely reported. ${ }^{13-17}$ Nakajima et al. ${ }^{13}$ studied the influence of the hydrophobic coating and MPL on a lab-scale $13 \mathrm{~cm}^{2}$ cell with two different coating loads as well as with and without MPL. They have shown that the combination of a hydrophobic coating with a MPL results in the best startup capability. Tabe et al. ${ }^{14}$ have studied the effect of a MPL inside a 25 $\mathrm{cm}^{2}$ fuel cell. They concluded that the amount of water inside the catalyst layer (CL) of cells with MPL is strongly reduced resulting in a better startup capability. Hirakata et al. ${ }^{15}$ concluded that the cold start performance slightly increases by including a supplementary hydrophilic GDL between MPL and the regular GDL inside a $30 \mathrm{~cm}^{2}$ cell. The slightly better performance is explained by a more effective

\footnotetext{
*Electrochemical Society Student Member.

**Electrochemical Society Member.

${ }^{\mathrm{z}}$ E-mail: Pierre.Boillat@psi.ch
}

water removal from the catalyst layer (CL). Mishler et al. ${ }^{16}$ investigated the influence of the PTFE loading (5 and 23\% PTFE) inside the MPL. They found that the degradation inside cells with low amounts of PTFE is significantly higher which can be attributed to the water accumulation at the interface GDL-CL. Ko et al. ${ }^{17}$ increased the thickness of the CL by extending the CL into the MPL. This results in a larger pore space for water accumulation during cell failure and has shown its potential to increase the cold start capability. Another finding has been published by Oszcipok et al. ${ }^{18}$ who reported that the hydrophobicity might degrade during the experiments, affecting the water accumulation.

In literature, the following electrochemical and imaging characterization techniques are reported: Electrochemical characterization is mainly performed as isothermal cold start, $5,7,10,14,19-24$ freeheating cold start, ${ }^{8,9,25-29}$ cyclic voltammetry ${ }^{18,30-32}$ or impedance spectroscopy. ${ }^{18,30,32}$ Characterization with imaging has been carried out with light, ${ }^{7,11,23,24,33}$ electrons, ${ }^{15,18,26,30,34} \mathrm{x}^{- \text {rays }}{ }^{10,35}$ and neutrons. ${ }^{4,5,16,32,36-38}$

All studies about effects of materials on the cold start capability, ${ }^{13-17}$ however, are lacking two crucial characteristics: Cellto-cell variations and in-situ water distribution. Thus, we present a statistical investigation of the cold start capability combined with high-resolution neutron radiography. The statistical investigation is based on more than 700 cold starts performed on five different cell configurations with at least two repetitions each (see Table I). As has been shown previously, ${ }^{12}$ experiments with small scale fuel cells enable the disclosure of hidden effects inside technical fuel cells. In

Table I. Material definition and number of experiments performed
with the five cell configurations used during the experiments at $-7.5^{\circ} \mathrm{C}$.

\begin{tabular}{lccccc} 
Configuration & 1 & 2 & 3 & 4 & 5 \\
\hline MPL & Yes & Yes & Yes & No & No \\
PTFE $/ \mathrm{wt} \%$ & 0 & 5 & 20 & 0 & 5 \\
Thickness $\mu \mathrm{m}$ & 230 & 230 & 230 & 190 & 190
\end{tabular}

GDL+ MPL

$\mathrm{CCM}$

No. of samples

No. of cold starts

Primea 5710

$\begin{array}{ccc}3 & 2 & 2 \\ 183 & 71 & 72\end{array}$


order to obtain an unprecedented insight of different material properties, the investigations presented here were performed on $1 \mathrm{~cm}^{2}$ differential cells. Furthermore, the experiments of cell-to-cell variations are of particular interest for fuel cell stacks of numerous of single cells with active areas in the order of hundreds of $\mathrm{cm}^{2}$. Imaging by neutron radiography serves to interpret the results of the statistical analysis and to understand the implications of the water distribution for the five cell configurations at subfreezing temperatures.

\section{Experimental}

Cell design.-The following experiments were performed on 15 fuel cells of an active area of $1 \mathrm{~cm}^{2}$ (see Table I). These cells were operated with the Multicell setup that enables the simultaneous operation of six cells with identical gas supply, humidification and temperature described previously. ${ }^{39}$ The subfreezing temperature was realized via a thermal bath, operated with a mixture of 50\% Ethylene-Glycol and water. The precise temperature was controlled via local heaters on the individual cells. In order to simulate a small portion of a technical fuel cell, the cells were operated in differential mode, ${ }^{40-45}$ consisting in operation under high stoichiometries $(>15)$ to ensure a homogeneous temperature distribution, humidification and gas composition along the channels. The flow field consists of 5 parallel flow channels (10 $\mathrm{mm}$ long, $1 \mathrm{~mm}$ wide and $0.55 \mathrm{~mm}$ deep) grooved inside an aluminum block which was subsequently gold coated. A more detailed description can be found in Ref. 39 .

In order to investigate the influence of the GDL material on the cold start capability, 5 different GDL with 0, 5, $20 \mathrm{wt} \%$ PTFE coating and with and without MPL were used, respectively (see Table I, SGL Carbon Group Series $24^{46}$ ). During the experiments, the materials were varied symmetrically on anode and cathode side. The GDL with MPL accounts for additional $40 \mu \mathrm{m}(230 \mu \mathrm{m})$ compared to the GDLs without MPL $(190 \mu \mathrm{m})$. Catalyst coated membranes (CCM) (Primea 5710 , Gore Ltd., USA) were used with Pt-loadings of $0.1 \mathrm{mg}_{\mathrm{Pt}} \mathrm{cm}^{-2}$ on the anode and $0.4 \mathrm{mg}_{\mathrm{Pt}} \mathrm{cm}^{-2}$ on the cathode side. In order to study statistical effects of the material distribution, several repetitions of each configuration were measured. The statistical analysis was performed at a temperature of $-7.5^{\circ} \mathrm{C}$, as under this condition the failures of the cells were distributed within $2 \mathrm{~h}$ of operation. ${ }^{12}$ The detailed numbers of cold starts executed at $-7.5^{\circ} \mathrm{C}$ with each cell configuration are listed in Table I. The number of cold start performed at $-10^{\circ} \mathrm{C}$ was limited to approximately 10 , as a much more repeatable behavior was obtained ${ }^{47}$ Due to the beam time constraints, only one experiment was performed with imaging for each cell configuration.

Experimental protocol.-All tests were performed with a slight overpressure of 100 mbar on both sides with cell flows of $0.1 \mathrm{NL} / \mathrm{min}$ on the anode and cathode side. The following protocol was carried out at -7.5 and $-10^{\circ} \mathrm{C}$ with the five cell configurations:

Step 1: Dry nitrogen was circulated at $25^{\circ} \mathrm{C}$ inside the cells until the cell resistance increased above $0.5 \mathrm{Ohm} \mathrm{\textrm {cm } ^ { 2 }}$.

Step 2: The cells were prehumidified with nitrogen $(50 \% \mathrm{RH})$ at $25^{\circ} \mathrm{C}$ during 20 minutes to ensure identical starting conditions.

Step 3: Humidification and gas flow was stopped and the cells were cooled down to the desired temperature.

Step 4: The cells were feed with reactant gases $\left(\mathrm{H}_{2}\right.$ and Air) until the cell voltage reached $0.9 \mathrm{~V}$ during $5 \mathrm{~s}$.

Step 5: Linear increase of current density during 1 minute to 0.1 $\mathrm{Acm}^{-2}$ (see Figure 1). Consecutive operation in galvanostatic mode until cell voltage decreases below $0.2 \mathrm{~V}$. This step was aborted after 2 hours of operation during the statistical analysis and 30 minutes inside the neutron beamline.

Step 6: After cell failure, the cells were heated up to $25^{\circ} \mathrm{C}$.

Data processing.-Mainly three different definitions to characterize the cold start capability of the fuel cells are reported in literature: the operating time, ${ }^{5,12}$ accumulated charge, ${ }^{18,48,49}$ or the amount of water produced. ${ }^{50,51}$ In this paper we decide to evaluate the cold start capability based on the operating time, which is the time from the start

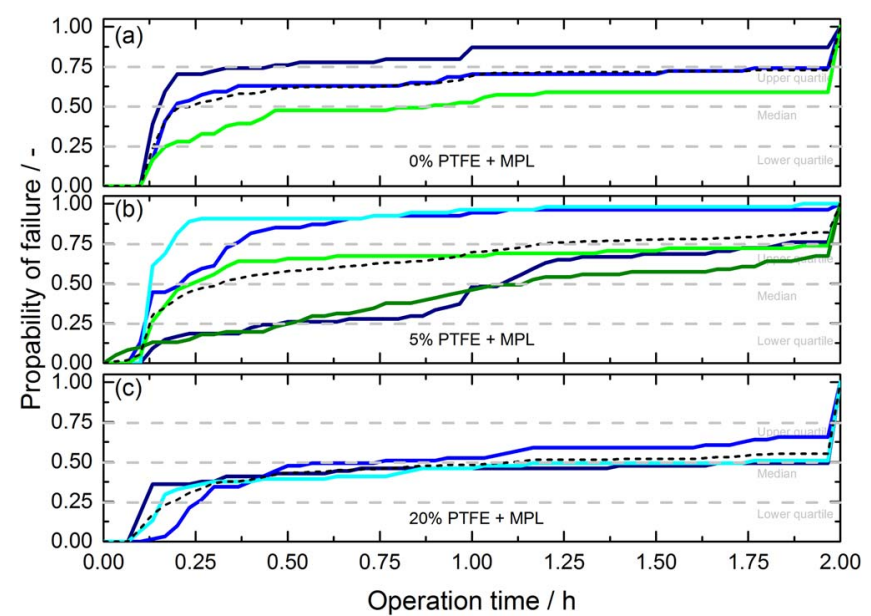

Figure 1. Accumulated probability of failure during a $2 \mathrm{~h}$ cold start at $-7.5^{\circ} \mathrm{C}$ operated with GDLs with MPL and (a) $0 \mathrm{wt} \%$, (b) $5 \mathrm{wt} \%$ and (c) $20 \mathrm{wt} \%$ PTFE coating. The solid lines in the graphic depict individual cells, the dotted line the probability distributions of all cells.

of current flow until the cell voltage drops below $0.2 \mathrm{~V}$ (see Figure 3 ). However, as the experiments were operated in galvanostatic mode, the accumulated charge $q_{c}$ can be simply calculated by integrating the current $i$ over the operating time.

Neutron imaging. - The neutron experiments were carried out at the ICON beamline s. $^{52}$ of the Swiss Spallation Neutron Source of PSI. The cells were imaged in in-plane configuration (membrane parallel to the beam axis) with a tilted imaging setup. ${ }^{41}$ With this imaging setup, a pixel size of $5 \times 60 \mu \mathrm{m} /$ pixel with an effective resolution (FWHM) of approx. $30 \mu \mathrm{m}$ across and $200 \mu \mathrm{m}$ along the membrane was obtained. The exposure time has been set to $20 \mathrm{~s}$. The camera was an Andor iKon-L with $2048 \times 2048$ pixels.

Image processing.-All images did undergo a pixel wise flat field correction, a median filter with $5 \times 5 \times 3(\mathrm{x}, \mathrm{y}, \mathrm{t})$, correction for scattered neutrons and an intensity correction of the neutron beam. Based on the neutron radiographs which were referenced pixel-wise to their radiograms in the dry state, the thickness of water $\delta$ was calculated according to the Lambert-Beer law. ${ }^{41}$

\section{Results}

Statistical analysis._-Figure 1 shows the accumulated probability of failure as function of the operating time for GDLs with (a) $0 \mathrm{wt} \%$, (b) $5 \mathrm{wt} \%$, (c) $20 \mathrm{wt} \%$ of PTFE with MPL at $-7.5^{\circ} \mathrm{C}$. The individual graphs (a-c) share a common $\mathrm{x}$-axis. The solid lines depict the histograms of the individual cells, the dashed line represents the probability distribution of all cells. In general, three interesting effects can be observed:

First, the data clearly indicates that the cold start capability differs strongly between the individual cells of 0 and $5 \mathrm{wt} \%$ PTFE, whereas the cells with $20 \mathrm{wt} \%$ PTFE show a more repeatable behavior. Consequently, the dashed lines in Figures $1 \mathrm{a}-1 \mathrm{~b}$ are not representative for material comparisons with low coating loads as the cell-to-cell variations are more dominant.

Second, a tendency of reduced probability of cell breakdown can be identified with increasing hydrophobic coating of the GDL; after $2 \mathrm{~h}$ of operation the cells with $20 \mathrm{wt} \%$ PTFE fail with a probability of around $50 \%$; cells with lower coating load around $75 \%$.

Third, mainly two scenarios of cold start can be classified: Type I occurs during the first 10-15 minutes of operation with a high risk of cell failure. After this period, the probability is significantly decreased and this category of cold start will be named Type II henceforth. As has already been described in Ref. 12, no cell failures occur during the 


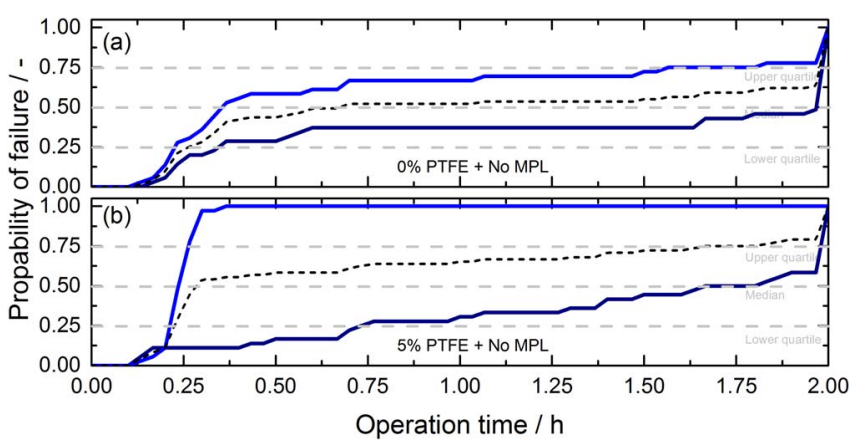

Figure 2. Accumulated probability of failure during a $2 \mathrm{~h}$ cold start at $-7.5^{\circ} \mathrm{C}$ operated with GDLs without MPL and (a) $0 \mathrm{wt} \%$ and (b) $5 \mathrm{wt} \%$ PTFE coating. The solid lines in the graphic depict individual cells, the dotted line the probability distributions of all cells.

first 3-5 minutes (temperature dependent), which can be explained by the water uptake of the membrane and the CL.

Figure 2 shows the accumulated probability of failure as a function of the operating time for GDLs with (a) $0 \mathrm{wt} \%$ PTFE, (b) $5 \mathrm{wt} \%$ of PTFE without MPL at $-7.5^{\circ} \mathrm{C}$. In general, similar trends with highly dominant cell-to-cell variations (especially Figure $2 b$ ) are observed. However, a significant difference can be identified during the first 10 minutes of operation compared to the cells with MPL. The cells without MPL seem to reach the lower quartile (25\% of cell failure) significantly later (around 15 minutes) compared to the cells with MPL (around 8 minutes). Furthermore, no cell failures are measured during the first 7 minutes with all cells.

Voltage peaks.-Figure 3 shows the detailed temporal evolution of the cell voltage during three cold starts of type I at $-10^{\circ} \mathrm{C}$ with three different coating loads $(0,5,20 \mathrm{wt} \%$ PTFE) including a MPL. $-10^{\circ} \mathrm{C}$ has been chosen as all cold starts fail within this time period at this temperature. In general, almost identical trends are obtained with minor variations in voltage and time between the three configurations. It can be observed that the evolution of the cell voltage can be subdivided into three phases. During the first period, the cell voltages stabilize and a steady state is reached. This equilibrium is maintained during approximately 2 minutes and a voltage peak of $2-3 \mathrm{mV}$ can be identified in minute 3 . Afterwards, the cell voltage decreases with a
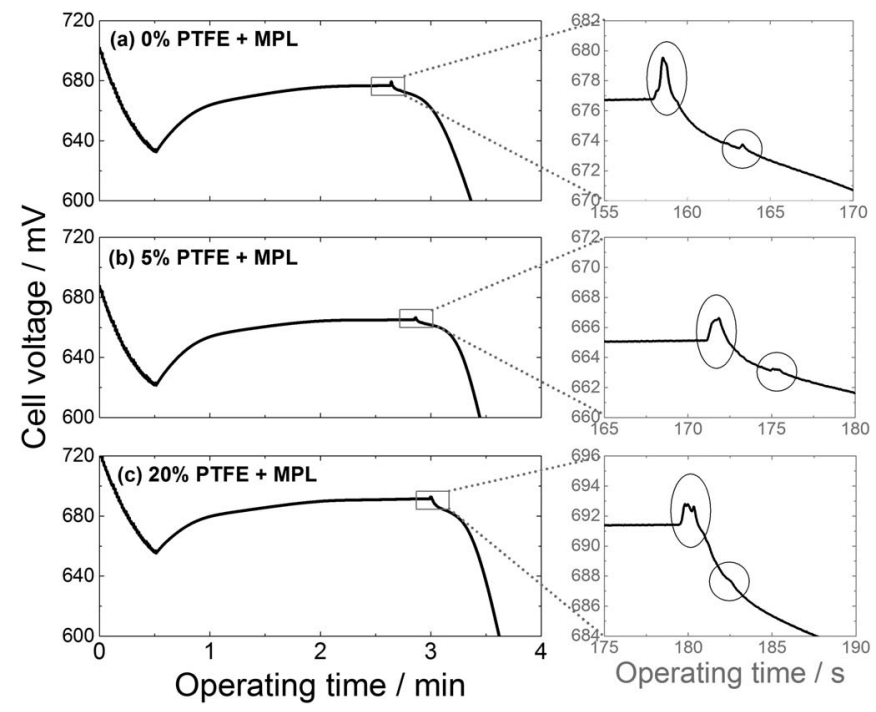

Figure 3. Three cold starts of type I at $-10^{\circ} \mathrm{C}$ operated with GDLs including an MPL and (a) $0 \mathrm{wt} \%$, (b) $5 \mathrm{wt} \%$ and (c) $20 \mathrm{wt} \%$ PTFE coating.
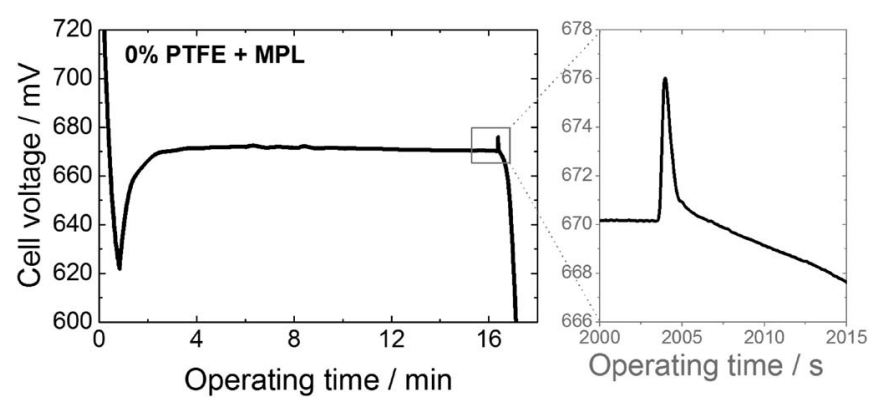

Figure 4. Example of cold start type II at $-7.5^{\circ} \mathrm{C}$ operated with a GDL with MPL and $0 \mathrm{wt} \%$ PTFE.

slope of 150-200 $\mathrm{mV} \mathrm{min}^{-1}$ during 3-4 minutes until it drops below $0.2 \mathrm{~V}$ when the current is automatically stopped. Hence, operating times in the range of 7-8 minutes are obtained, perfectly fitting with the probability distributions presented in Figure 1. It has to be mentioned that a second voltage peak is observable $3-5 \mathrm{~s}$ after the previous peak, being almost one order of magnitude smaller compared to the previous peak. The chosen cold starts in Figure 3 are representative for all Type I cold starts performed with the three configurations.

In case of a Type II cold start (operating times $>10$ minutes) a similar voltage peak can be identified initiating the cell voltage drop (see Figure 4). Although the shape of the voltage peak is similar compared to a cold start Type I, the height of the voltage peak is significantly increased $(6 \mathrm{mV})$ which will be explained later on in the discussion part.

Figure 5 depicts the cell voltage during a cold start of Type I of PEFCs without MPL with (a) $0 \mathrm{wt} \%$ PTFE and (b) $5 \mathrm{wt} \%$ PTFE. At first glance, significant differences are visible in the results obtained for the cell with (a) and without (b) PTFE. However, it has to be mentioned that substantial cell-to-cell variations were identified during the breakdown of the cell configuration without MPL and without PTFE (see Figure 2). Hence, no characteristic cold start could be identified representing all individual tests. Although the evolution of the cell voltage is rather unrepeatable, all cold starts have shown at least two distinct voltage peaks of similar height.

The cell without MPL and 5 wt\% PTFE (see Figure 5b) shows a similar behavior compared to the cells with MPL. However, two main differences can be observed: First, the voltage drop is initiated with two distinct peaks of heights above $1 \mathrm{mV}$ and peak heights up to $6 \mathrm{mV}$ are obtained at cold start of type I. Second, the operating time of a cold start of type I is significantly longer compared to the cold start performed with MPL.
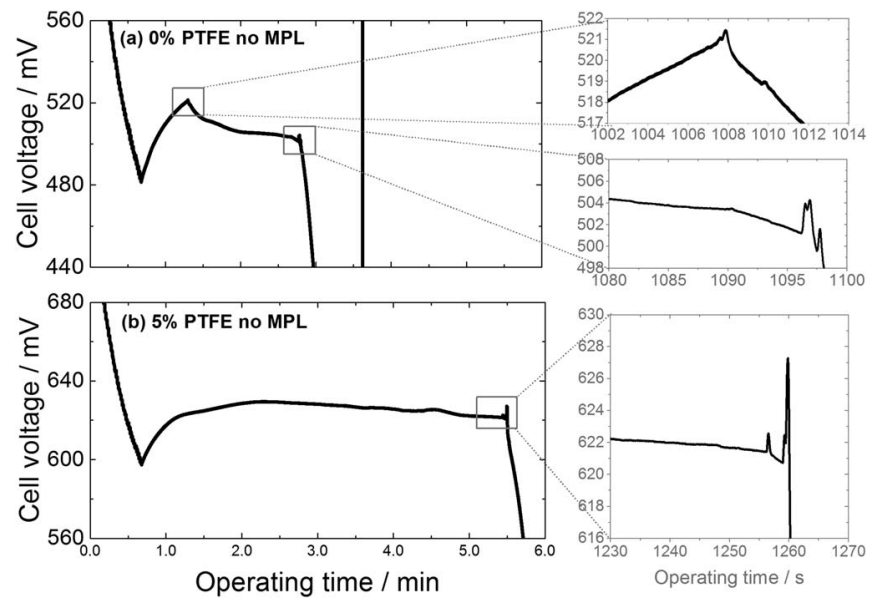

Figure 5. Two cold starts of type I at $-10^{\circ} \mathrm{C}$ operated with GDLs without MPL and (a) $0 \mathrm{wt} \%$ and (b) $5 \mathrm{wt} \%$ PTFE coating. 


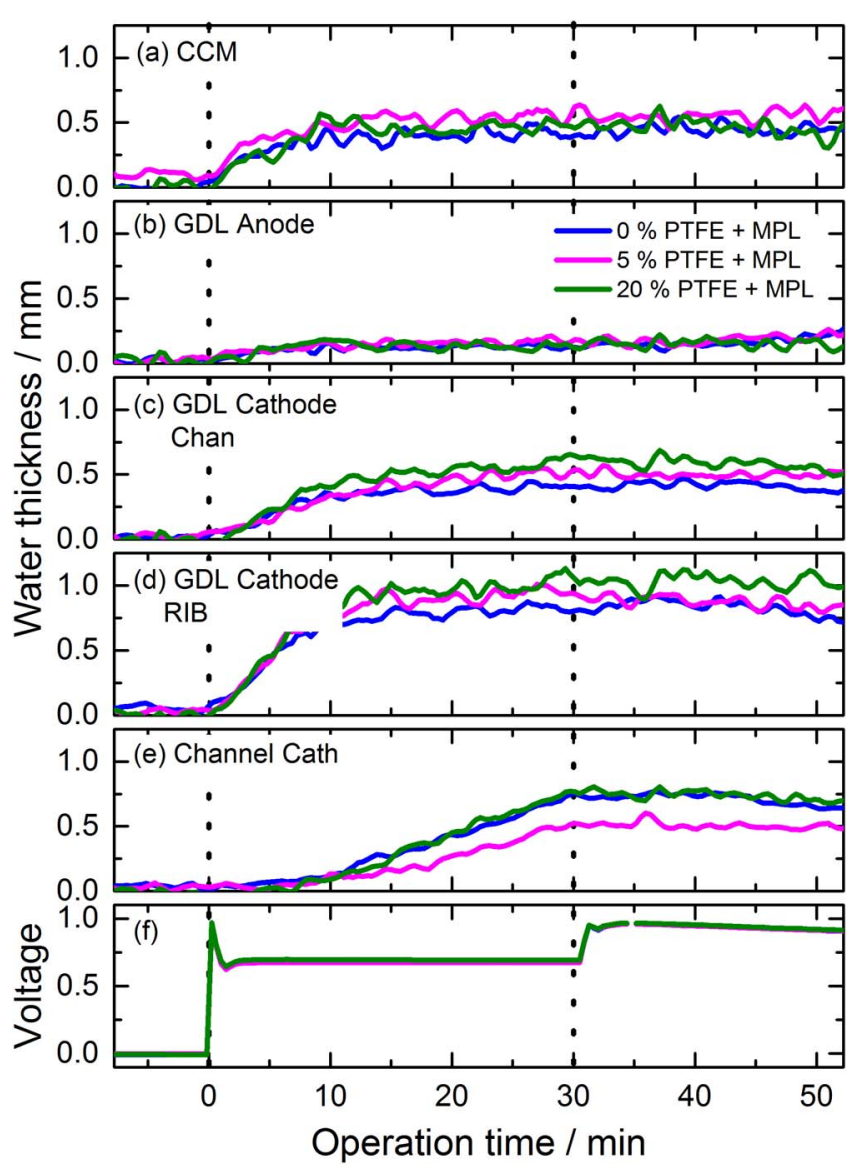

Figure 6. Integral amount of water during a cold start of $-7.5^{\circ} \mathrm{C}$ in the (a) CCM, (b) Anode GDL, (c) Cathode GDL under the channel, (d) Cathode GDL under the land and inside the (e) channel of the cathode flow field of three cell of different PTFE coating load with MPL. (f) depicts the temporal evolution of the cell voltage.

Integral water distribution.-Figure 6 depicts the integral amount of water in (a) the CCM, (b) the anode GDL and MPL, (c) the cathode GDL and MPL under the land of the flow field, (d) the cathode GDL and MPL under the channel of the flow field, (e) inside the flow channel of the cathode, and (f) the cell voltage during an isothermal cold start at $-7.5^{\circ} \mathrm{C}$ of 30 minutes. The three colors depict the different PTFE loadings $(0,5,20 \mathrm{wt} \%$ PTFE) of the GDLs. During this experiment, all cells were able to run through the entire 30 minutes of operation (cold start type II).

The amount of water inside the CCM increases during the first 10 minutes and remains constant during the entire experiment for all three cell configurations (see Figure 6a). It has to be mentioned that the integration area of the CCM accounted for only 8 pixel rows in horizontal direction, as the pixel resolution was $5 \mu \mathrm{m} /$ pixel. Hence, the water thickness in this region will give us only an indication about the amount of water inside and around the CCM. However, as all five cell configurations are analyzed with the same procedure, comparisons between the cells are suitable.

In the anode GDL and MPL (see Figure 6b), only very little water accumulates, as the back diffusion is rather low at these temperatures, which is in good agreement with previous studies performed with neutron radiography. ${ }^{4,5}$ The amount of water inside the cathode GDL (see Figures $6 c-6 d)$ is significantly higher and increases continuously during the first 15 minutes of operation. As demonstrated previously, ${ }^{53,54}$ water preferentially accumulates under the ribs. It requires around 15 minutes to reach the steady state, which is significantly longer compared to the stabilization inside the CCM. Although the GDL of the three cell configurations are coated with different amounts of PTFE,
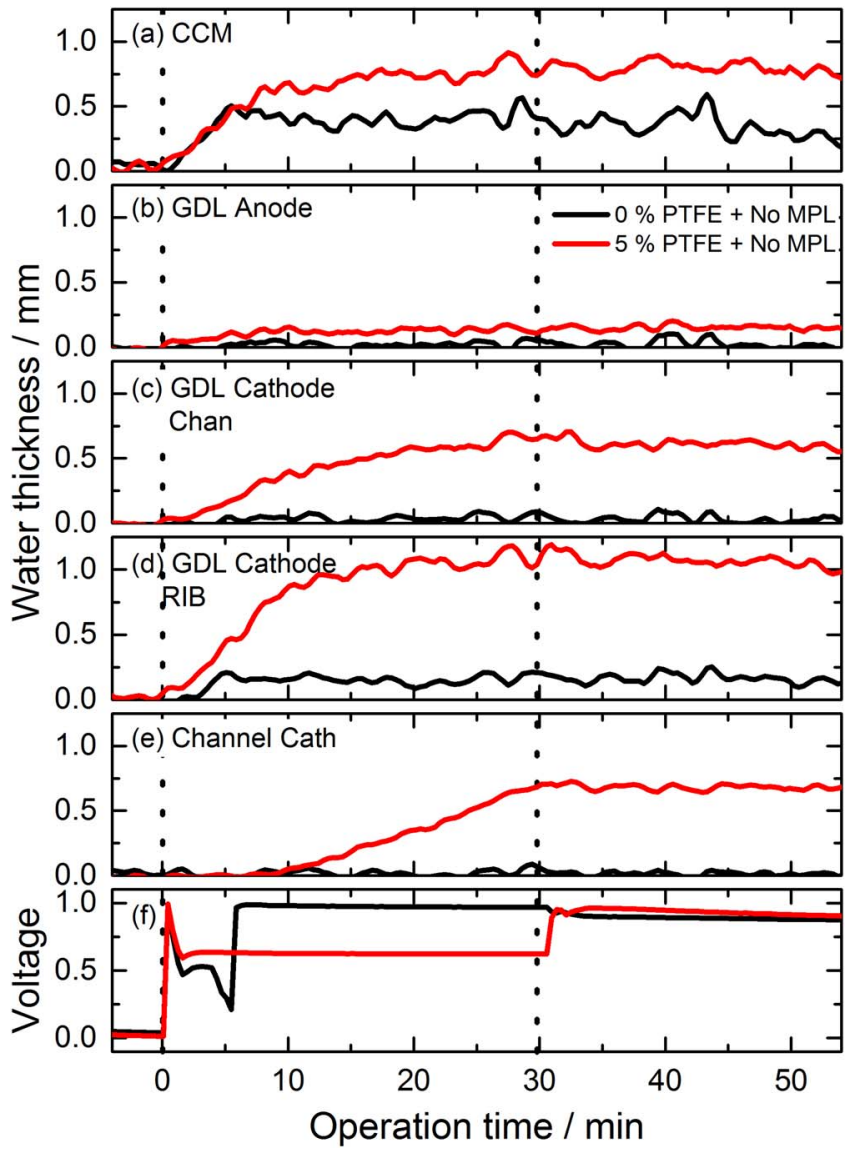

Figure 7. Integral amount of water during a cold start of $-7.5^{\circ} \mathrm{C}$ in the (a) CCM, (b) Anode GDL, (c) Cathode GDL under the channel, (d) Cathode GDL under the land and inside the (e) channel of the cathode flow field of two cell of different PTFE coating load without MPL. (f) depicts the temporal evolution of the cell voltage.

all three cell configurations show a similar integral quantity of water inside the GDL, which is in good agreement with previous findings from our group. ${ }^{55}$ Regarding the accumulation of water inside the flow channel of the cathode, water starts to accumulate after 10 minutes of operation, which indicates that first preferential pathways of water are created inside the GDL. The cell with the highest coating load accumulates less water which can be explained by a better removal of water droplets on the surface of the GDL thanks to the increased surface contact angle.

In analogy, Figure 7 depicts the integral amount of water in the different layers of the two cell configurations without MPL. Unfortunately, no cell of configuration 4 ( $0 \mathrm{wt} \%$ PTFE, no MPL) was able to be operated through the entire 30 minutes of the experiment inside the beamline. This is not a systematic characteristic of this material combination, as other cell mounts with the same material did show longer and stochastic operating time in the experiments without imaging. However, this experiment nicely shows that the cells undergoing a cold start of Type I do not only accumulate water inside the CCM, but also inside the GDL under the ribs.

Nevertheless, an increased amount of water can be measured in the region of the CCM compared to the cells with MPL, which is in good agreement with literature. ${ }^{39}$ Besides that, the water distributions and the times scales of equilibration in the different layers are very similar compared to the cells with MPL.

Local water distribution.-Figure 8 shows the local water distribution after 30 minutes of operation at $-7.5^{\circ} \mathrm{C}$ for all 5 cell configurations. The water thickness is depicted in a false color code, 

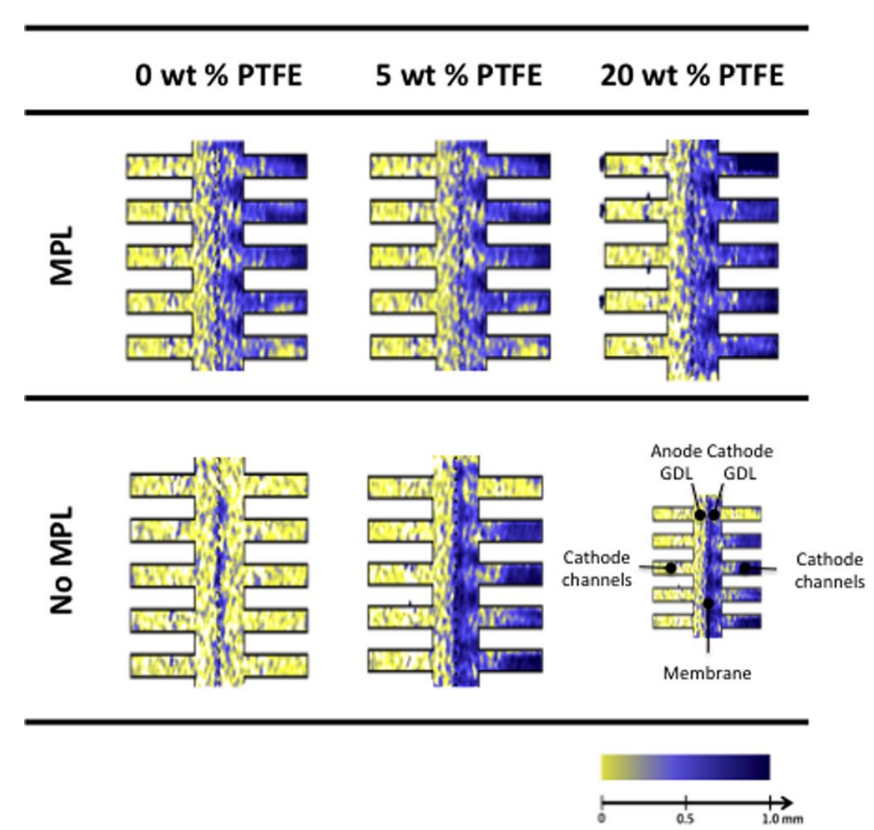

Figure 8. Local water distribution of the five different cell configurations after 30 minutes of operation at $-7.5^{\circ} \mathrm{C}$ (except for the cell without PTFE and without MPL, which failed after 5 minutes of operation). The dotted line in the middle of the radiograph represents the membrane, with its anode on the left and cathode on its right. The alternating structure on the left and right represents the flow field. The GDLs are located between the dotted line and the bottom of the flow fields.

representing $0 \mathrm{~mm}$ of water (yellow) and $1 \mathrm{~mm}$ of water (blue). The dotted line in the middle of the radiograph represents the membrane, with its anode on the left and cathode on its right. The alternating structure on the left and right represents the flow field. The GDLs are located in between the dotted line and the bottom of the flow fields. As described in the experimental part, the effective resolution has been enhanced in direction perpendicular to the membrane. Hence, the radiographs are magnified by a factor of approximately 6 in $\mathrm{x}$ direction. The images are averaged over a time period of 15 minutes after the cell failure. The neutron radiographs presented hereafter are the resulting water distributions obtained from the cold starts that are presented in Figure 6 and Figure 7. As can be seen, the water distribution inside the cells including a MPL is rather similar. Water preferentially accumulates under the lands of the flow fields, the region between the CL and GDL shows a relatively low amount of water. In contrast, the cell without MPL shows significantly more water accumulation in the region of the CCM. As mentioned before, no cell of the configuration without PTFE coating and without MPL was able to be operated for 30 minutes in the beamline to obtain reasonable saturation levels.

\section{Discussion}

Types of cold start.-In Figure 1 and Figure 2 two different time scales of freezing were identified: High probability during the first ten minutes, succeeded with a region of significantly reduced number of failures. Cold starts of Type I occur during the first 10-15 minutes, meanwhile a steady increase of the saturation levels is measured inside the CCM and the MPL/GDL of the cathode side (see Figure 6 and Figure 7). After this timeframe, the amount of water stabilizes inside the MPL as well as GDL and a linear growth of the water thickness can be identified inside the cathode flow field. Based on the saturation levels, one can deduce the water transport mechanism. During the rise of the water thickness inside the porous layers, water pathways are created from the CL toward the flow channels. First pathways are gen- (a)

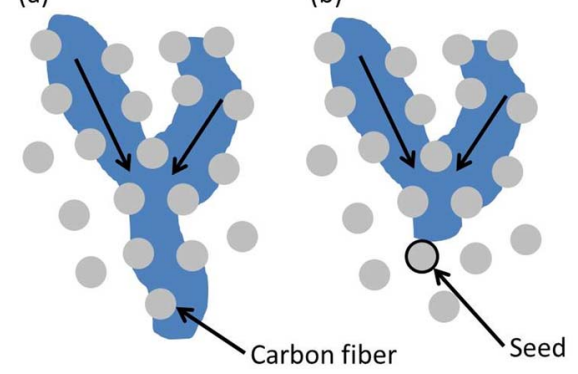

(c)

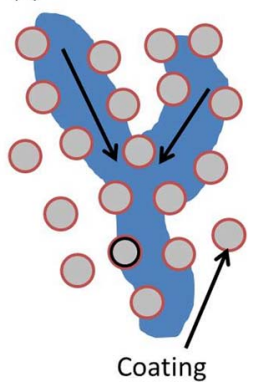

Figure 9. Schematics of freezing inside (a) uncoated GDL without seed, (b) uncoated GDL with seed and (c) coated GDL with seed.

erated after 10 minutes, when initial water accumulation is identified inside the flowfield. The creation of the pathways is completed after 15 minutes, as the saturation levels stabilize inside the porous layers.

This water transport has a significant impact on the freezing probability. As has been explained in the introduction, the phase transition from supercooled water to ice can be triggered by a seed. In general a seed represents any kind of impurity or structure, which increases the probability of triggering a heterogeneous nucleation of supercooled water. Inside fuel cells, these seeds can be either defects like e.g. fiber breaks, asperities or micro cracks but also any kind of boundary surfaces like e.g. carbon fibers. During the creation of the water pathways through the porous layers, two scenarios are possible: First, the water cluster does not pass by a seed (see Figure 9a); no freezing occurs and the cell can be successfully operated during the first 15 minutes. Second, a seed is encountered during the growth of the water cluster (see Figure 9b); the phase transition is induced and the cell fails during this time period. However, if the water pathways are created after 15 minutes of operation and the saturation levels reach a steady state, water permeates along these water clusters (so called preferential pathways) with a significantly reduced probability of facing a seed and hence cell breakdown. Consequently, these transport mechanisms identified by neutron radiography could clearly explain the statistical differences in Figure 1 and Figure 2 between cold start of type I and II.

Period of zero-failure.-During the experiments, a period of zerofailure was identified with all operating temperatures and GDL materials used (see Figure 1 and Figure 2). At the beginning of the cold start, product water is taken up from the hydrophilic membrane until a maximal hydration state is reached. According to literature values, ${ }^{20}$ a maximum amount of approximately $0.05 \mathrm{mg} \mathrm{cm}^{-2}$ of water can be taken up by the membrane (neglecting lateral diffusion of water under the sealings). According to our protocol which comprises a linear increase of current density to $0.1 \mathrm{Acm}^{-2}$ during the first minute of operation, enough product water is already present after 30 s to saturate the membrane. However, as can be clearly seen in a previous publications of our group, ${ }^{4,12}$ more than 1 minute is required to stabilize the high frequency resistance (HFR) and thus the hydration state of the membrane, which can be explained by the differential operating

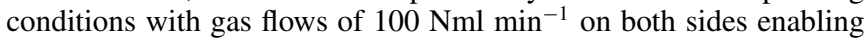
the water uptake of up to $0.44 \mathrm{mg} \mathrm{min}^{-1}$ of water at $-10^{\circ} \mathrm{C}$ (according to the Goff Gratch equation for partial pressures below $0^{\circ} \mathrm{C}^{56}$ ). Consequently, the results obtained during the first 1.5-2 minutes of the present protocol can be mainly explained by the water uptake of the membrane.

Subsequently, liquid water starts to accumulate inside the void space of the CL. As can be seen in Figure 3, fuel cells undergoing a cold start Type I can be operated for 1-2 more minutes (after the HFR stabilized) until the freezing event can be identified based on the voltage peak and an increase in the membrane resistance. Similar to the water uptake of the membrane, this step is highly dependent on the evaporation rate, as $78 \%$ of the product water can be taken up by 
evaporation on the anode and cathode side. However with increasing operating time, the probability of supercooled water to freeze increases due to a higher likelihood of facing a seed as well as due to its increased cluster size. $^{11}$

Although these calculations are in good agreement with our experimental results (see Figure 1 and Figure 3), contradictory findings are reported in literature. ${ }^{20}$ In these models, good agreement is obtained between experiments and models by coupling the cold start capability with the water uptake of the membrane and the CL void volume, neglecting the evaporation rate. These reported experiments have two major differences: First, these investigations were performed on labscale fuel cells operated at technical operating conditions, where the evaporation rate plays a minor role. Second, as these experiments were performed on lab-scale fuel cells of $50 \mathrm{~cm}^{2}$, cell failures occur in a repeatable manner with high probability after short operating times. ${ }^{12}$ Based on these two differences, the freezing mechanism of larger labscale fuel cells operated under technical operating conditions appears to be different on the global scale even though the freezing mechanism is identical on the local scale.

Influence of MPL on period of zero-failure.-Besides the influence of the temperature presented previously in Ref. 12, differences between the period of zero - failure of cells with and without MPLs were observed. During the first 5 minutes of operation, no cell failures were measured with cells including MPLs. This time period was slightly increased in cells without MPL being able to be operated during 7.5 minutes without any cell failure at $-7.5^{\circ} \mathrm{C}$. This is an interesting fact, as the period of zero-failure is identical for fuel cells of technical as well as for small scale size. The difference can be explained by a different water accumulation inside the fuel cells. In cells without MPL, water tends to accumulate as a dense layer near the CL/GDL interface instead of spreading over the thickness of the GDL as when a MPL is used. This can be seen in Figure 8, consistently with our previous measurements. ${ }^{39,63}$ Such a dense layer will contact less of the carbon surface and reduce the probability of facing a seed, in particular during the initial period where the water has not broken through the GDL yet. An influence of temperature can also be considered, as a higher thermal contact resistance can be expected when no MPL is used. However, assuming a contact resistance in the range of $1 \cdot 10^{-4} \mathrm{~K} \cdot \mathrm{m}^{2} \cdot \mathrm{W}^{-1}$ (in absence of published numbers for the CL/GDL interface, the numbers reported in the literature ${ }^{64}$ for the GDL/Flow Field interface are used) and with a heat production in the order of magnitude of $1 \cdot 10^{-3} \mathrm{~W} \cdot \mathrm{m}^{-2}$ corresponding to our current density of $0.1 \mathrm{~W} \cdot \mathrm{cm}^{-2}$, this effect should only account for a temperature increase of $0.1^{\circ} \mathrm{C}$.

Period of cell breakdown.-The period of the cell breakdown (time between voltage peak until the cell voltage drops below $0.2 \mathrm{~V}$ ) can be explained by the filling of the void space of the CL with ice after the first nucleation of supercooled water. Assuming a porosity of $50 \%,{ }^{57}$ a maximal storage capacity of $0.4 \mathrm{mg} \mathrm{cm}^{-2}$ of water is obtained with our materials. At a current density of $0.1 \mathrm{Acm}^{-2}, 0.56 \mathrm{mg} \mathrm{min}^{-1}$ of water is produced, which would result in a maximal time-scale of around $40 \mathrm{~s}$ until failure. However, similar to previous explanations, the evaporation rate of water has to be taken into account. As first water/ice already condenses inside the porous layers of the cathode side of the fuel cell (see Figure 6) the gas stream is saturated and only little amount of water/ice can be removed via the cathode side; thus water removal is mainly driven by evaporation via the anode gas stream. Consequently a rate around $0.22 \mathrm{mg} \mathrm{min}^{-1}$ at $-10^{\circ} \mathrm{C}$ and 0.33 $\mathrm{mg} \min ^{-1}$ at $-5^{\circ} \mathrm{C}$ can be removed by evaporation. Thus, a voltage drop between 1-2 minutes can be explained in order to fill the entire pore space of the catalyst layer and thus block all active sides, in good agreement with experimental findings (Figure 3 and Ref. 12).

Influence of coating on cold start capability.-In the statistical analysis in Figure 1 the coating load has been identified as being a crucial parameter for repeatability; with low coating loads significant cell-to-cell variations were identified, which were considerably

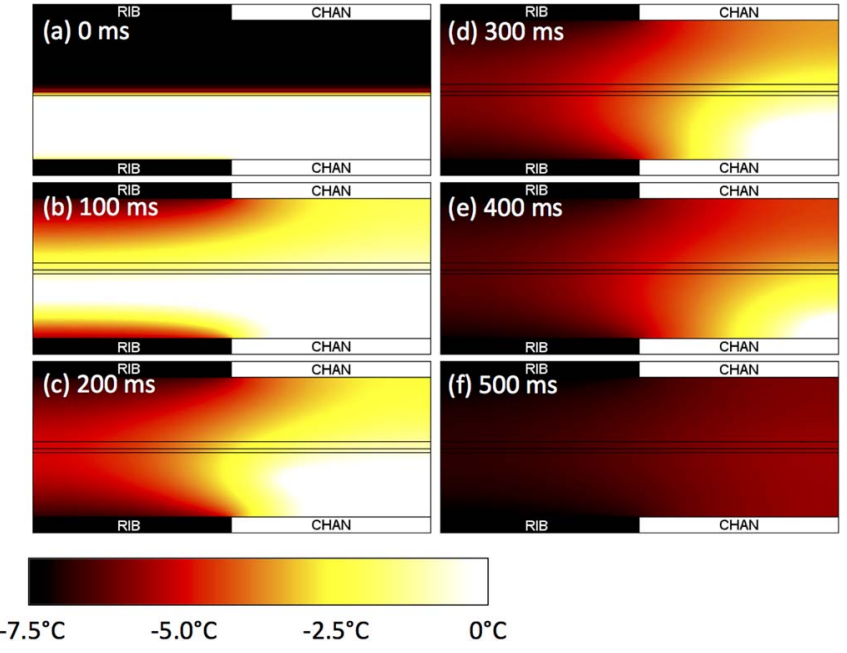

Figure 10. Results of 2D transient thermal model during freezing event. In this model, an instantaneous propagation of the ice seed over the entire area of the cell is assumed, which leads to an immediate freezing of approximately $20 \%$ of the water until the local temperature reaches $0^{\circ} \mathrm{C}$

reduced with $20 \mathrm{wt} \%$ PTFE. These variations can be explained by the morphology of the used GDL materials. As has been observed with SEM,${ }^{55}$ the used GDLs comprise a highly porous carbon binder, which can act or host seeds for crystal growth during the cold start. With increasing coating load ( $>10 \mathrm{wt} \%$ PTFE), this carbon binder is covered with a homogeneous layer of PTFE ${ }^{55}$ and the probability of encountering a seed is reduced (see Figure 9c). With this model, the minor cell-to-cell variations as well as the reduced overall probability of cell failure of highly coated GDLs can be explained.

Explanation of voltage peaks.-In our experiments, voltage peaks were identified shortly before cell failure. Variations of the cell voltage can be induced by e.g. temperature, pressure, or humidification. In the present experiments, these voltage peaks can be most likely explained by an increase of the local temperature resulting from the latent heat $\left(336 \mathrm{Jg}_{\mathrm{H} 2 \mathrm{O}}{ }^{-158}\right)$ released while undergoing a phase transition from supercooled water into ice. According to our estimation (see supplementary information), the temperature sensitivity of the cell voltage should be approximately $1.4 \mathrm{mV} \cdot \mathrm{K}^{-1}$, translating into temperatures increases between $1-2^{\circ} \mathrm{C}$ and $4{ }^{\circ} \mathrm{C}$ for the peaks seen in Figure 3 and Figure 4, respectively. To assess whether this assumption is realistic, we have performed a numerical simulation (see details in supplementary information) using a 2D transient thermal model. In this model, an instantaneous propagation of the ice seed over the entire area of the cell is assumed, which leads to an immediate freezing of approximately $20 \%$ of the water until the local temperature reaches $0{ }^{\circ} \mathrm{C}$. The freezing of the remaining liquid water as well as the temperature decrease to the initial temperature $\left(-7.5^{\circ} \mathrm{C}\right)$ is limited by the heat conduction through the GDL and other materials. According to our simulation (see Figure 10), all the water is frozen after $400 \mathrm{~ms}$ and the average CL temperature has returned to its initial value within 600 $\mathrm{ms}$ after the start of freezing. The assumption of instantaneous seed propagation is not exact, as it is known from the literature ${ }^{65}$ that the propagation speed is in the order of $10-20 \mathrm{~mm} \cdot \mathrm{s}^{-1}$ for the considered temperature, representing a total propagation time of $0.5 \mathrm{~s}-1 \mathrm{~s}$ for our cell size. A full 3D transient thermal calculation including seed propagation is out of the scope of this work, but an approximation of the impact of seed propagation can be obtained by convoluting the temperature response function in the time domain with a rectangle function having the expected duration of the seed propagation. The result of such a convolution with a $0.5 \mathrm{~s}$ propagation time is shown in Figure 11, point out the reduction of the peak temperature increase and a slight broadening of the peak duration. The obtained results 


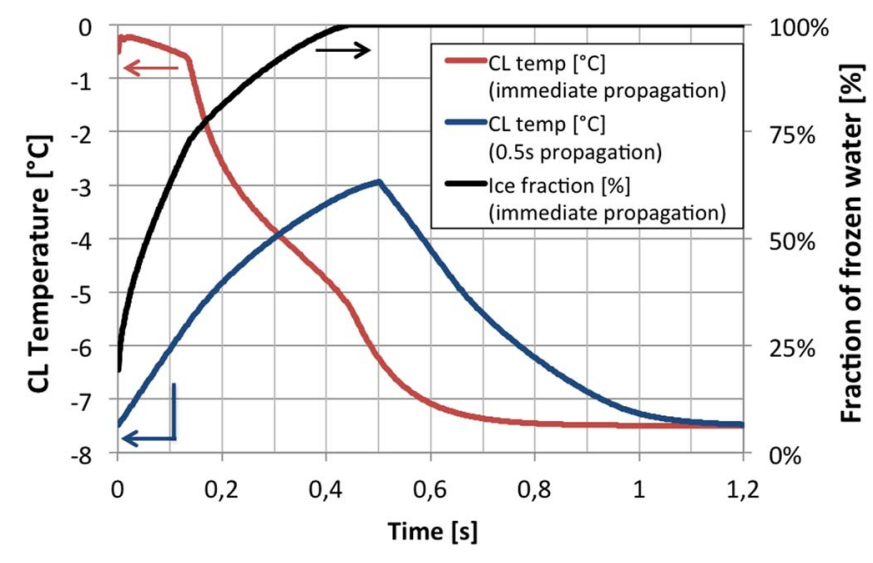

Figure 11. Temporal evolution of the temperature inside the catalyst layer (CL) under the assumption of immediate freezing and freezing propagation inside the fuel cell. Furthermore, the ice fraction during the freezing event is included in the figure.

are approximate due to several assumptions in the model, but their good agreement with the temporal evolution and magnitude of the observed voltage peaks indicate that our assumption for the origin of these peaks is realistic.

Explanation of multiple voltage peaks. - The second voltage peak observed in Figure 3 and Figure 5 can be most likely related to the interconnectivity of the water cluster. These peaks were mainly identified in Type I cold starts with failures below 10 minutes of operation. As has been observed in the neutron radiographs, the water pathways are not fully created and a maximal saturation level in the GDL is not reached in this timeframe. Hence, the full interconnectivity of the water cluster in the GDL might not been established, which would lead to a separate freezing with two distinct voltage peaks.

This assumption would also be able to explain the differences between the cells with and without MPL. As has been observed with $\mathrm{X}$-Ray tomography, ${ }^{59}$ the water is more clustered inside GDLs without MPL, which might lead to an independent freezing with more distinct voltage peaks. Furthermore, the disappearance of the second voltage peak in cold starts of Type II can be nicely explained with this phenomenon. Based on the neutron radiographs, a steady state condition of the saturation level is reached which is assumed to be highly interconnected. ${ }^{60}$ This fact might not only explain the disappearance of the second voltage peak but also the significantly higher voltage peak compared to separate water cluster in Type I cold starts. A distinction needs to be made between multiple peaks occurring apparently randomly as in the case of Figure $5 \mathrm{a}$ (one peak at $\mathrm{t}=$ 1 min and one peak at $\mathrm{t}=3 \mathrm{~min}$ ) and double peaks occurring in an apparently correlated way with a few seconds in between (e.g. as in Figure 5b). The first of these cases is consistent with the assumption of distinct clusters of water over different areas of the cell, whose freezing will occur independently from each other. The second case can rather be explained by a not completely formed water network on the local scale, where freezing of one part of the network will force more water in the remaining pores, triggering their encounter with a frozen section. This applies in particular for the case of the cells without MPL, where water coming out of the electrode with result in the filling of several dead-ended pathways.

Influence of water distribution on freezing.-Our previous results demonstrated $^{12}$ that the cluster volume and hence the water distribution has a significant impact on the freezing behavior of PEFCs. The neutron radiographs in Figure 8 have clearly shown that the amount of water around the cathode CL is significantly reduced in cells with MPLs. However, the water clusters are not expected to be entirely separated between water inside the CL and the GDL. If this as the case, the probability of freezing would be reduced. More likely, the water volume of a water cluster in cells with MPL is expected to be increased compared to cell without MPL, as liquid water is transported via only a certain number of cracks of the MPL $(\sim 100$ cracks $\mathrm{cm}^{-2}$ ), similar to a point-like injection. ${ }^{61}$ This assumption is in good agreement with X-Ray tomography measurements of operating fuel cells without MPL, ${ }^{59}$ where water cluster are not entirely connected with each other.

Hence, it is expected that the propagation of the freezing of cells including a MPL occurs instantaneously. This behavior can be clearly observed in Figure 3, where one distinct voltage peak is measured; the second voltage peak is significantly smaller. In case of locally separated water cluster, several voltage peaks of similar height would be expected. This effect might explain the particular behavior of the cell without MPL and PTFE in Figure 5a. Two voltage peaks of comparable amplitude have been identified after a very short operating time, where the water cluster can be assumed to be not interconnected in the GDL as only little amount of water was accumulated (see Figure 7a).

Thermodynamic transition from supercooled to frozen water.As has been reported previously, ${ }^{11}$ the free energy change of phase transition from water to ice is more positive (less exothermic) with higher coating loads of Teflon at a critical cluster size below $5 \mathrm{~nm}$. This calculation is based on a spherical droplet accumulating on a flat surface. The critical cluster size is obtained by an equilibrium of a surface $(\mathrm{dG}>0)$ and volume term $(\mathrm{dG}<0)$. Water is not accumulating in the form of droplets but rather as a continuous water cluster across the different porous layer of the PEFC. ${ }^{59,62}$ Consequently, in reality water accumulates more as a network of cylinders than spheres. This results in a completely different surface-to-volume ratio, which is more favorable to maintain supercooled water. Hence, this can explain the rather stable occurrence of this metastable phase, which is longer maintained for GDLS with higher coating loads.

Technical application.--In order to evaluate whether the significantly improved cold start capability of cells with highly coated GDLs can be extrapolated to technical applications (see Figure 1), previously presented Monte-Carlo simulation ${ }^{12}$ was applied to the experimental data; the numerical results are plotted in Figure 12. Although significant differences are identified between the different materials with small scale fuel cells, the simulation clearly shows the limited impact for cell sizes above $10 \mathrm{~cm}^{2}$.

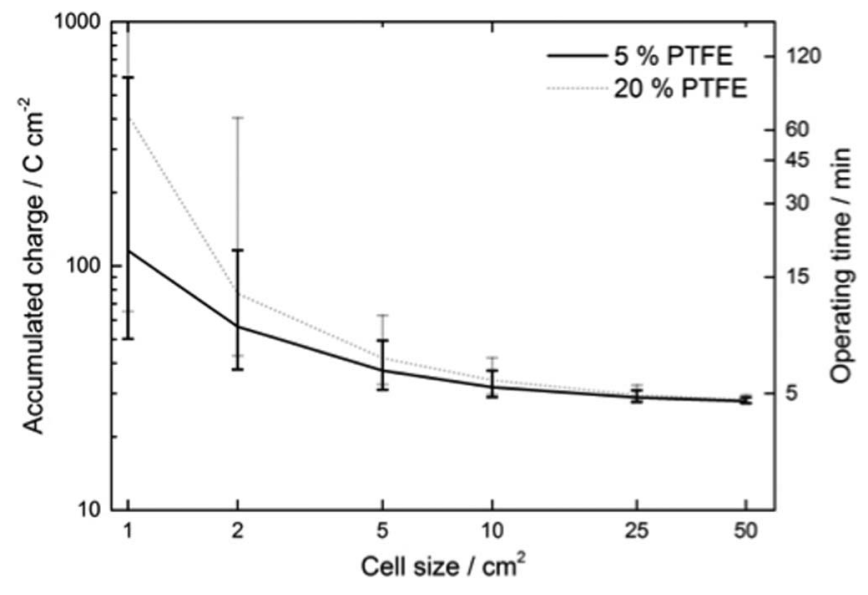

Figure 12. Modelling results from Monte-Carlo simulation: Comparison between two GDL materials with different hydrophobic coating load as a function of its cell size at $-7.5^{\circ} \mathrm{C}$ and $0.1 \mathrm{Acm}^{-2}$. 


\section{Conclusions}

In this paper, a statistical analysis of the freezing behavior was performed on small-scale fuel cells combined with high resolution neutron radiography in order to study the influence of different hydrophobic coating loads and the existence of an MPL. The following key findings were obtained:

- Cell-to-cell variations are more dominant than influences of the materials variations at low coating loads: In the statistical analysis, a higher coating load reduces the cell-to-cell variations. This effect can be explained by the microstructure of the GDL and MPL materials, which varies strongly inside a material and acts as a seed for ice nucleation. With high coating loads, the seeds are covered by the hydrophobic coating. However, no significant differences were identified between the materials with low coating loads.

- Failures of cold start mainly occur during the first 10 minutes of operations: This effect can be explained by the creation of water pathways from the CL to the flowfield. After having created these water pathways, water is mainly transported along these preferential pathways, resulting in a highly reduced probability of facing a new seed for nucleation.

- Cells without MPL decrease the cell failure during the first 10 minutes of operation: The statistical analysis of the cold start has identified that no cell failure occurs in the first 7.5 minutes of operation with cells without MPL, whereas cells with MPL fail with a higher probability in this timeframe.

- Latent heat of freezing can be identified by voltage peaks: In the experiments, voltage peaks of several $\mathrm{mV}$ were measured shortly before cell failure. This effect has been attributed to an increase of the temperature induced by the latent heat of freezing.

- For technical applications GDLs with alternative MPL formulations and high coating loads might be optimized materials for improved cold start capability. However, numerical results of a MonteCarlo simulation have shown limited impact above a cell size of $10 \mathrm{~cm}^{2}$

\section{Acknowledgments}

This work was carried out with the support of the European Community. We appreciate the support of the European Research Infrastructure H2FC (funded under the FP7 specific programme Capacities, grant Agreement Number 284522). The Commission for Technology \& Innovation and the Swiss Competence Center for Energy Research (SCCER): Efficiency in Mobility are greatly acknowledged for supporting this work.

\section{References}

1. T. Yoshida and K. Kojima, The Electrochemical Society Interface, 24, 45 (2015).

2. T. W. Lim, in Transition to Renewable Energy Systems, p. 183, Wiley-VCH Verlag GmbH \& Co. KGaA (2013).

3. K. Sekizawa, N. Kitamura, K. Manabe, Y. Nonobe, M. Kizaki, and K. Kojima, ECS Transactions, 33, 1947 (2010).

4. J. Biesdorf, P. Oberholzer, F. Bernauer, A. Kaestner, P. Vontobel, E. H. Lehmann, T. J. Schmidt, and P. Boillat, Phys Rev Lett, 112 (2014)

5. P. Oberholzer, P. Boillat, R. Siegrist, R. Perego, A. Kästner, E. Lehmann, G. G. Scherer, and A. Wokaun, Journal of The Electrochemical Society, 159, B235 (2011).

6. Z. M. Wan, H. W. Chang, S. M. Shu, Y. X. Wang, and H. L. Tang, Energies, 7, 3179 (2014).

7. Y. Ishikawa, H. Harnada, M. Uehara, and M. Shiozawa, J Power Sources, 179, 547 (2008).

8. M. Sundaresan and R. M. Moore, J Power Sources, 145, 534 (2005)

9. E. Schiesswohl, T. von Unwerth, F. Seyfried, and D. Bruggemann, J Power Sources, 193, 107 (2009).

10. I. Mayrhuber, F. Marone, M. Stampanoni, T. J. Schmidt, and F. N. Büchi, ChemElectroChem, 2, 1551 (2015).

11. Y. Ishikawa, M. Shiozawa, M. Kondo, and K. Ito, Int J Heat Mass Tran, 74, 215 (2014)

12. J. Biesdorf, P. Stahl, M. Siegwart, T. J. Schmidt, and P. Boillat, Journal of The Electrochemical Society, 162, F1231 (2015).

13. H. Nakajima, T. Konomi, and T. Kitahara, J Power Sources, 171, 457 (2007).

14. Y. Tabe, M. Saito, K. Fukui, and T. Chikahisa, J Power Sources, 208, 366 (2012).
15. S. Hirakata, M. Hara, K. Kakinuma, M. Uchida, D. A. Tryk, H. Uchida, and M. Watanabe, Electrochim Acta, 120, 240 (2014).

16. J. Mishler, Y. Wang, P. P. Mukherjee, R. Mukundan, and R. L. Borup, Electrochimica Acta, 65, 127 (2012).

17. J. Ko, W.-G. Kim, Y.-D. Lim, and H. Ju, International Journal of Hydrogen Energy, 38, 652 (2013).

18. M. Oszcipok, D. Riemann, U. Kronenwett, M. Kreideweis, and A. Zedda, J Power Sources, 145, 407 (2005).

19. A. D. Santamaria, J. Bachman, and J. W. Park, Electrochim Acta, 107, 327 (2013).

20. E. L. Thompson, J. Jorne, W. Gu, and H. A. Gasteiger, Journal of The Electrochemical Society, 155, B625 (2008).

21. C. Chacko, R. Ramasamy, S. Kim, M. Khandelwal, and M. Mench, Journal of The Electrochemical Society, 155, B1145 (2008).

22. E. Pinton, Y. Fourneron, S. Rosini, and L. Antoni, J Power Sources, 186, 80 (2009).

23. S. H. Ge and C. Y. Wang, Electrochim Acta, 52, 4825 (2007).

24. S. Ge and C.-Y. Wang, Electrochemical and Solid-State Letters, 9, A499 (2006).

25. K. Jiao, I. E. Alaefour, G. Karimi, and X. Li, International Journal of Hydrogen Energy, 36, 11832 (2011).

26. Q. G. Yan, H. Toghiani, Y. W. Lee, K. W. Liang, and H. Causey, J Power Sources, 160, 1242 (2006)

27. F. Jiang, W. Fang, and C.-Y. Wang, Electrochim Acta, 53, 610 (2007)

28. R. K. Ahluwalia and X. Wang, J Power Sources, 162, 502 (2006).

29. R. Fu, U. Pasaogullari, D. S. Hussey, D. L. Jacobson, and M. Arif, ECS Transactions, 11, 395 (2007).

30. J. Hou, B. Yi, H. Yu, L. Hao, W. Song, Y. Fu, and Z. Shao, International Journal of Hydrogen Energy, 32, 4503 (2007).

31. S. Ge and C.-Y. Wang, Journal of The Electrochemical Society, 154, B1399 (2007).

32. R. Mukundan, Y. S. Kim, T. Rockward, J. R. Davey, B. Pivovar, D. S. Hussey, D. L. Jacobson, M. Arif, and R. Borup, ECS Transactions, 11, 543 (2007).

33. K. Tüber, D. Pócza, and C. Hebling, J Power Sources, 124, 403 (2003).

34. J. Li, S. Lee, and J. Roberts, Electrochim Acta, 53, 5391 (2008).

35. J. Roth, M. R. Zurbrügg, S. Irvine, F. Marone, M. Stampanoni, and F. N. Büchi, ECS Transactions, 58, 453 (2013).

36. R. Mukundan, R. Lujan, J. R. Davey, J. S. Spendelow, D. S. Hussey, D. L. Jacobson, M. Arif, and R. Borup, ECS Transactions, 25, 345 (2009).

37. R. Mukundan, J. Davey, R. Lujan, J. Spendelow, Y. S. Kim, D. S. Hussey, D. Jacobson, M. Arif, and R. L. Borup, ECS Transactions, 16, 1939 (2008).

38. A. Santamaria, H.-Y. Tang, J. W. Park, G.-G. Park, and Y.-J. Sohn, International Journal of Hydrogen Energy, 37, 10836 (2012).

39. P. Oberholzer, P. Boillat, R. Siegrist, A. Kastner, E. H. Lehmann, G. G. Scherer, and A. Wokaun, Electrochem Commun, 20, 67 (2012).

40. I. A. Schneider, M. H. Bayer, and S. von Dahlen, Journal of The Electrochemical Society, 158, B343 (2011).

41. P. Boillat, Advanced characterization of polymer electrolyte fuel cells using high resolution neutron imaging in PHD Thesis, Eidgenössische Technische Hochschule ETH Zürich, Nr. 18397, PHD Thesis, Eidgenössische Technische Hochschule ETH Zürich (Nr. 18397), Zürich (2009).

42. P. Sauriol, D. S. Nobes, X. T. Bi, J. Stumper, D. Jones, and D. Kiel, Journal of Fuel Cell Science and Technology, 6, 041014 (2009).

43. Y. Tabuchi, T. Shiomi, O. Aoki, N. Kubo, and K. Shinohara, Electrochim Acta, 56, $352(2010)$

44. J. Li, C.-Y. Wang, and A. Su, Journal of The Electrochemical Society, 155, B64 (2008).

45. T. Kadyk, S. Kirsch, R. Hanke-Rauschenbach, and K. Sundmacher, Electrochim Acta, 56, 10593 (2011).

46. SGL TECHNOLOGIES GmbH, GDL 24 \& 25 Series Gas Diffusion Layer, Technical data sheet, in (2014)

47. J. Biesdorf, P. Stahl, M. Siegwart, T. J. Schmidt, and P. Boillat, J. Electrochem. Soc., 162, 1231 (2015).

48. M. Oszcipok, A. Hakenjos, D. Riemann, and C. Hebling, Fuel Cells, 7, 135 (2007).

49. M. Oszcipok, M. Zedda, D. Riemann, and D. Geckeler, J Power Sources, 154, 404 (2006).

50. K. Tajiri, Y. Tabuchi, and C.-Y. Wang, Journal of The Electrochemical Society, 154, B147 (2007).

51. K. Tajiri, Y. Tabuchi, F. Kagami, S. Takahashi, K. Yoshizawa, and C. Y. Wang, $J$ Power Sources, 165, 279 (2007)

52. A. P. Kaestner, S. Hartmann, G. Kühne, G. Frei, C. Grünzweig, L. Josic, F. Schmid, and E. H. Lehmann, Nuclear Instruments and Methods in Physics Research Section A: Accelerators, Spectrometers, Detectors and Associated Equipment, 659, 387 (2011).

53. N. Pekula, K. Heller, P. A. Chuang, A. Turhan, M. M. Mench, J. S. Brenizer, and K. Ünlü, Nuclear Instruments and Methods in Physics Research Section A: Accelerators, Spectrometers, Detectors and Associated Equipment, 542, 134 (2005).

54. P. Krüger, H. Markötter, J. Haußmann, M. Klages, T. Arlt, J. Banhart, C. Hartnig, I. Manke, and J. Scholta, J Power Sources, 196, 5250 (2011).

55. J. Biesdorf, P. Oberholzer, T. J. Schmidt, and P. Boillat, ECS Transactions, 64, 467 (2014).

56. Smithsonian Meteorological Tables, ed. R. J. List, Smithsonian Institution, Washington, 1984.

57. K. Neyerlin, W. Gu, J. Jorne, and H. A. Gasteiger, Journal of the Electrochemical Society, 153, A1955 (2006).

58. H. McArthur and D. Spalding, Engineering Materials Science: Properties, Uses, Degradation, Remediation, Elsevier Science (2004). 
59. J. Eller, T. Rosén, F. Marone, M. Stampanoni, A. Wokaun, and F. N. Büchi, Journal of The Electrochemical Society, 158, B963 (2011).

60. P. K. Sinha and C. Y. Wang, Electrochim Acta, 52, 7936 (2007)

61. J. T. Gostick, M. A. Ioannidis, M. W. Fowler, and M. D. Pritzker, Electrochemistry Communications, 11, 576 (2009).

62. C. Ziegler and D. Gerteisen, J Power Sources, 188, 184 (2009).
63. P. Boillat, P. Oberholzer, E. H. Lehmann, G. G. Scherer, and A. Wokaun, in MRS Proceedings. Vol. 1528. Cambridge University Press, 2013.

64. Khandelwal, Manish, and M. M. Mench, Journal of Power Sources 161.2, 1106 (2006).

65. B. F. Ryan and W. C. Macklin. "The growth of ice in supercooled aqueous solutions." Journal of Crystal Growth 2.6, 337 (1968). 